\title{
Can triggers be cumulative in inducing heart attack in soccer game spectators?
}

\author{
Tasch, Christoph ; Larcher, Lorenz
}

\begin{abstract}
Emotional stress and excitement associated with watching soccer matches has been suggested to act as an external trigger for the onset of acute coronary syndromes. We report about a patient of Italian nationality who developed acute coronary syndrome while watching the European football championship match Switzerland vs. Turkey in 2008. Although greater emotional intensity was possibly involved while watching his country play two days earlier (Italy vs Netherlands), he developed no symptoms. Hence, this case throws some interesting light on what can be considered as an acute trigger by discussing the assumption of a cumulative effect regarding to the potential trigger two days before and in which way psychological stress may have influence on the onset of acute coronary syndromes
\end{abstract}

DOI: https://doi.org/10.1007/s10354-012-0137-5

Posted at the Zurich Open Repository and Archive, University of Zurich ZORA URL: https://doi.org/10.5167/uzh-155828

Journal Article

Published Version

Originally published at:

Tasch, Christoph; Larcher, Lorenz (2012). Can triggers be cumulative in inducing heart attack in soccer game spectators? Wiener Medizinische Wochenschrift, 162(15-16):337-339.

DOI: https://doi.org/10.1007/s10354-012-0137-5 


\title{
Can triggers be cumulative in inducing heart attack in soccer game spectators?
}

\author{
Christoph Tasch, Lorenz Larcher
}

Received: 17 August 2011 / Accepted: 17 January 2012 / Published online: 3 August 2012 (C) Springer-Verlag Wien 2012

\section{Möglichkeit eines kumulativen Triggereffektes hinsichtlich der Auslösung von akuten Koronarsyndromen bei Zuschauern von Fußballspielen?}

Zusammenfassung Emotionaler Stress bei Zuschauern von Fußballspielen wurde in der Literatur als möglicher Auslöser für das Auftreten von akuten Koronarsyndromen beschrieben. Wir berichten über einen in der Schweiz lebenden Patienten italienischer Nationalität, bei dem es während des Spiels Schweiz gegen Türkei im Rahmen der Fußball-Europameisterschaft 2008 zum Auftreten eines akuten Koronarsyndroms kam. Im Vergleich dazu kam es zwei Tage zuvor während des Spiels Italien gegen Niederlande zu keiner Manifestation eines Myokardinfarkts, obwohl möglicherweise wegen der Identifikation des Patienten mit der italienischen Mannschaft infolge der nationalen Zugehörigkeit eine größere emotionale Belastungssituation angenommen werden kann. Es wird daher die Frage aufgeworfen, in wie weit ein Trigger von einem grundsätzlichen ätiologischen Faktor abgrenzbar ist und ob möglicherweise zwischen beiden potentiellen Auslösern kumulative Effekte hinsichtlich der Manifestation des akuten Koronarsyndroms bestehen.

Schlüsselwörter: Akutes Koronarsyndrom, Myokardinfarkt, Auslöser, Trigger, Fußball

\footnotetext{
C. Tasch, MD $(\triangle)$

Glatzstrasse 30, 6020 Innsbruck, Austria

e-mail: christoph.tasch@gmx.net

C. Tasch, MD

Division of Cardiac and Vascular Surgery,

University Hospital Zurich, Zurich, Switzerland

L. Larcher, MD

Department of Plastic, Aesthetic, and Reconstructive Surgery,

Academic Teaching Hospital Feldkirch, Feldkirch, Austria
}

Summary Emotional stress and excitement associated with watching soccer matches has been suggested to act as an external trigger for the onset of acute coronary syndromes. We report about a patient of Italian nationality who developed acute coronary syndrome while watching the European football championship match Switzerland vs. Turkey in 2008. Although greater emotional intensity was possibly involved while watching his country play two days earlier (Italy vs Netherlands), he developed no symptoms. Hence, this case throws some interesting light on what can be considered as an acute trigger by discussing the assumption of a cumulative effect regarding to the potential trigger two days before and in which way psychological stress may have influence on the onset of acute coronary syndromes.

Keywords: Acute coronary syndromes, Myocardial infarction, Trigger, Soccer events

\section{Introduction}

A number of studies have examined the relationship between external triggers and the onset of acute coronary syndromes ranging from physical activity to emotional upset and unusual stress. A trigger in general has been defined as an activity that produces acute physiologic or pathophysiological changes leading directly to the onset of acute cardiovascular disease [1]. So triggering is basically a matter of physiological reactions to impulses and extern stimuli from the outside world. Emotional stress and excitement associated with watching soccer matches has been suggested to act as an external trigger for the onset of acute coronary syndromes (ACS), though this has been disputed by other studies that find the relationship, if any, between the two negligible [2-9]. 


\section{Case description}

At the Division of Cardiology of the University Hospital Zurich a patient was treated who had developed acute coronary syndromes while watching a soccer game. The case throws some interesting light on what can be considered as an acute trigger and in which way psychological stress may have influence on the onset of acute coronary syndromes. A 57-year-old man presented to the Emergency Unit before midnight on the 11th of June 2008 with left thoracic chest pain persistence with radiation to the neck. These symptoms developed while he was watching the European football championship match Switzerland versus Turkey in 2008 at about 10 min after the first goal of the match was scored by the Swiss Team. The Italian patient is a taxi driver by profession living in Switzerland for more than ten years. His family history was negative and his cardiovascular risk factors were hyperlipidemia, hypertension and cigarette smoking. No prior disorders and diseases were known. The patient reported being interested in soccer, but not a fan of either team. Interestingly, although he was an Italian, watching the game when the Italian Team had played at around the same time two days earlier had caused no symptoms (The Italian Team lost as well as the Swiss Team: Italy vs Netherlands $\left[26^{\prime}, 31^{\prime}, 80^{\prime}\right]$ 0:3/Swiss [32'] vs Turkey [57', 93'] 1:2;-as seen Goals were scored nearly at the same time concerning the hazard period on 11th [Swiss 32'] and comparable period on 9th [Netherlands 26']). The patient reported having had two attacks of chest pain lasting 1-2 min 14 days before. There was no known history of coronary heart disease. The initial ECG showed a ST Elevation in II, III and aVF and CK-Max was raised up to $942 \mathrm{U} / 1$. An acute coronary angiography demonstrated total occlusion of the RCA in the proximal third. In the main steam of the LCA was no stenosis; in the RIVA and RCX were only diffuse changes without significant stenosis. PTCA including stent implantation was successfully performed. As given in anamnesis life style habits did not change substantially in association with the beginning of the European Soccer Cup on the 7th of June 2008. The patient stated that he did not have any changes of job strain, physical activity or nutrition in the weeks before myocardial infarction. In particular the patient was questioned about potential triggers in the last 24 hours before symptom onset such as unusual physical activity, emotional upsets or immoderate alcohol consumption. As a result no other potential trigger could be identified.

\section{Discussion}

The case of our patient suggests the following: 1) Not watching one's favourite team win or lose acts as an acute trigger of ACS, as suggested by previous studies, but rather the overall excitement with which the game is watched.2) Triggers might be cumulative. A series of triggers each of which is not strong enough to induce ACS, might collectively be able to do just that. In the case of our pati- ent, although greater emotional intensity was possibly involved while watching his country play two days earlier (Italy vs Netherlands), he developed no symptoms, whereas watching a game where he had little emotional involvement acted as a trigger for the acute event. However, since the patient had been living in Switzerland for many years, this may influence his personal attitude towards the Swiss national team and may lead to a higher emotional involvement than he admitted. There is no general agreement about how long before the onset of symptoms an activity can take place to be regarded as an acute trigger rather than a more general etiologic factor. Trigger studies typically assess activities in the period ranging from a few minutes to 24 hours before ACS onset. Most recently, attention has focused on a 1- to 2-hour period before the onset of symptoms [10]. Sympathetic overtone appears to be the main cause in triggering acute coronary syndromes and plaque rupture and subsequent thrombosis at the site of plaque rupture is the most common underlying pathophysiological mechanism of acute coronary syndromes [11, 12]. This means that an increased sympathetic activity correlates with a bigger risk. What is determining is the traversing of a threshold, which is rather likely to occur the higher the extent of pathomorphological deviations in the coronary vessels in regard to atherosclerosis or the vulnerability of the plaque. Tofler and Muller have conjectured that there is an inverse association between the degree of plaque vulnerability and the intensity of the trigger required to produce rupture and thrombosis [13]. Thus, an individual with an extremely vulnerable plaque or severe stenosis may develop occlusion without a demonstrable trigger, whereas someone with no vulnerable lesion or stenosis may require a major identifiable stressor to trigger plaque rupture and thrombosis. In the case of our patient there may have been an extremely vulnerable plaque, but it raises the question why the acute myocardial infarction did not occur 2 days before under the influence of a comparable trigger. Therefore, it can also be hypothesized, that the susceptibility for the onset of acute myocardial infarction has been increased. Psychological stress stimulates the sympathetic nervous system leading to increased concentration of circulating catecholamines. Alterations in hypothalamic-pituitary-adrenocortical activity and inflammatory cytokine responses may also be involved [14]. In patients suffering from atherosclerotic diseases mental stress induces increased activities of coagulation as well as a decrease in fibrinolytic activation $[15,16]$ and it is known that in this patient the stress-induced hypercoagulability [17] as well as the platelet activation [18] needs more time to recover once the stressor has come to an end. The endocrine and inflammatory responses take longer to evolve and persist for longer periods after the end of behavioural challenges in regard to psychological stress than does neural activation [14] and may result in persistent platelet activation, hypercoagulable state and activation of inflammatory processes. These effects may have been playing a role in this case of potentially concurrent or interacting triggers 
and why myocardial infarction occurred in a potentially not so emotional game, because of the consecutively increased susceptibility for the onset of acute coronary syndromes after the influence of the first trigger two days before and the possibly associated proneness to plaque rupture and thrombosis on the day of myocardial infarction. Insight into triggering and identifying the pathophysiological mechanisms might be helpful for a better understanding, why an infarct enters just now and offers an additive approach to prevention. This seems also important because of the fact that risk factors cannot reveal anything about causality, but only about statistical relationships, and thus play only auxiliary roles. Only $50 \%-75 \%$ of the cardiovascular events can be traceable to traditional risk factors $[12,19]$. Thus, besides risk-prediction models investigating the underlying mechanisms of acute triggers, for example by involving assessments of hemostatic, endocrine and inflammatory responses to potential triggers would be a chance to facilitate the progress in the understanding of coronary heart disease and may clarify the pathophysiological mechanisms underlying the triggering process.

\section{Conflict of interest}

CT and LL have no competing interests to declare.

\section{References}

1. Muller JE, Abela GS, Nesto RW, et al. Triggers, acute risk factors and vulnerable plaques: the lexicon of a new frontier. J Am Coll Cardiol, 23: 809-813, 1994.

2. Wilbert-Lampen U, Leistner D, Greven S, et al. Cardiovascular events during World Cup soccer. N Engl J Med, 358: 475-483, 2008.

3. Witte DR, Bots ML, Hoes AW, et al. Cardiovascular mortality in Dutch men during 1996 European football championship: longitudinal population study. BMJ, 321(7276): 1552-1554, 2000.

4. Carroll D, Ebrahim S, Tilling K, et al. Admissions for myocardial infarction and World Cup football: database survey. BMJ, 325(7378): 1439-1442, 2002.

5. Katz E, Metzger JT, Marazzi A, et al. Increase of sudden cardiac deaths in Switzerland during the 2002 FIFA World Cup. Int J Cardiol, 107: 132-133, 2006.
6. Barone-Adesi F, Vizzini L, Merletti F, et al. It is just a game: lack of association between watching football matches and the risk of acute cardiovascular events. Int J Epidemiol, 39: 1006-1013, 2010.

7. Kirkup W, Merrick DW. A matter of life and death: population mortality and football results. J Epidemiol Community Health, 57: 429-432, 2003.

8. Brunekreef B, Hoek G. No association between major football games and cardiovascular mortality. Epidemiology, 13: 491-492, 2002.

9. Culic V. Football matches and acute cardiac events: potential effects of a complex psychosocial phenomenon on cardiovascular health. Int J Epidemiol 40: 1422-1425, 2011.

10. Strike PC, Steptoe A. Behavioral and emotional triggers of acute coronary syndromes: a systematic review and critique. Psychosom Med, 67: 179-186, 2005.

11. Naghavi M, Libby P, Falk E, et al. From vulnerable plaque to vulnerable patient: a call for new definitions and risk assessment strategies: Part I. Circulation, 108: 1664-1672, 2003.

12. Naghavi M, Libby P, Falk E, et al. From vulnerable plaque to vulnerable patient: a call for new definitions and risk assessment strategies: PartII. Circulation, 108: 1772-1778, 2003.

13. Tofler GH, Muller JE. Triggering of acute cardiovascular disease and potential preventive strategies. Circulation, 114: 1863-1872, 2006.

14. Strike PC, Magid K, Whitehead DL, et al. Pathophysiological processes underlying emotional triggering of acute cardiac events. Proc Natl Acad Sci USA 103: 4322-4327, 2006.

15. von Känel R, Dimsdale JE. Effects of sympathetic activation by adrenergic infusions on hemostasis in vivo. Eur J Haematol, 65: 357-369, 2000.

16. von Känel R, Mills PJ, Ziegler MG, et al. Effect of beta2adrenergic receptor functioning and increased norepinephrine on the hypercoagulable state with mental stress. Am Heart J, 144: 68-72, 2002.

17. Preckel D, von Kanel R. Regulation of hemostasis by the sympathetic nervous system: any contribution to coronary artery disease? Heartdrug, 4: 123-130, 2004.

18. Strike PC, Magid K, Brydon L, et al. Exaggerated platelet and hemodynamic reactivity to mental stress in men with coronary artery disease. Psychosom Med, 66: 492-500, 2004.

19. Magnus $P$, Beaglehole R. The real contribution of the major risk factors to the coronary epidemics: time to end the "only-50\%" myth. Arch Intern Med, 161: 2657-2660, 2001. 